\title{
A NOVEL MICROMACHINED GLOW PLUG FOR ULTRAHIGH TEMPERATURE IGNITION APPLICATIONS
}

\author{
Li-Anne Liew, Victor M. Bright, and Rishi Raj \\ Center for Advanced Manufacturing and Packaging of Microwave, Optical and Digital Electronics (CAMPmode), \\ Department of Mechanical Engineering, University of Colorado at Boulder \\ Boulder, Colorado 80309-0427; http://mems.colorado.edu
}

\begin{abstract}
This paper presents the design, fabrication and testing of a micro glow plug for ultrahigh temperature ignition applications. The device was fabricated from a novel refractory ceramic known as polymer-derived silicon carbon-nitride, which has been shown to possess outstanding mechanical robustness, corrosion resistance, and thermal shock resistance at temperatures exceeding $1000{ }^{\circ} \mathrm{C}$. The micro glow plug has been shown to achieve temperatures of at least $1200{ }^{\circ} \mathrm{C}$, with a response time of less than 1 second and with a power consumption of 3 Watts. In addition, the micro glow plug was used to ignite thermite in both chip-scale and macro-scale reactions.
\end{abstract}

\section{INTRODUCTION}

Glow plugs are temperature ignition devices commonly employed in diesel and natural gas engines [1]. Figure 1 shows a photograph of conventional, commercially available glow plugs and a schematic of the glow tip (the hot section) which typically consists of three components: a heating element, encasing material, and an outer sheath. The major figures of merit for glow plugs are achievable temperature $\left(1200{ }^{\circ} \mathrm{C}\right)$, response time, power consumption, and cost.

Several drawbacks are associated with these devices: Three different materials and manufacturing processes are required to fabricate the glow tip thus driving up device cost. The device is large (due to the manufacturing processes used) yet the entire heating element heats up to the maximum temperature $\left(1200{ }^{\circ} \mathrm{C}\right)$, leading to high power consumption (20-100 Watts) and slow response (5-10 seconds).
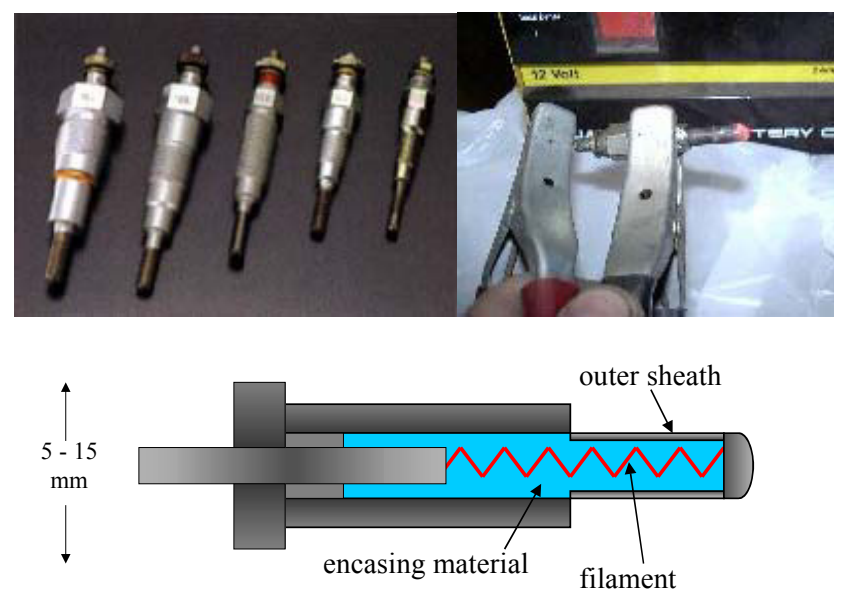

Figure 1. Above: Photographs of conventional diesel glow plugs, typical length 30-50 mm. Photos courtesy of Robert Bosch Corp. (http://www.bosch.com). Below: Schematic of the major components of a glow plug.
Temperature ignition in diesel engines (or any other hightemperature ignition applications for that matter) is therefore a prime application that could benefit from the reduced size, response time and power consumption offered by microsystems. However, until now no MEMS technology existed that could fulfill this need because the materials in the traditional MEMS infrastructure - silicon, polymers, metals and even many ceramics - cannot remain operational when temperatures exceed $1000{ }^{\circ} \mathrm{C}$ in oxidizing environments.

Our group has developed a technology to fabricate MEMS from a novel refractory material called silicon carbon nitride [2] ( $\mathrm{SiCN}) . \mathrm{SiCN}$ is a new class of amorphous polymer-derived bulk ceramics that remain mechanically stable to temperatures exceeding $1500{ }^{\circ} \mathrm{C}$ [2] and which exhibit excellent oxidation and creep resistance at those temperatures [2]. Our previous work has resulted in functional but commonplace devices such as electrostatic actuators [3] and thermal actuators [4] that were simply reproduced in SiCN since our focus was microfabrication.

Now, however, this marriage of a novel refractory material with an appropriate microfabrication technology has produced a revolutionary new concept in harsh environment applications (such as high-temperature ignition) that will enable Microsystems to enter markets previously untouched by MEMS.

In this work, a Micro Glow Plug was designed and fabricated from polymer-derived $\mathrm{SiCN}$. When compared to conventional glow plugs, the MGP exhibits faster response time and lower power consumption. The MGP was successfully used to ignite thermite, a solid-state explosive with ignition temperature of 1200 ${ }^{\circ} \mathrm{C}$, in both chip-scale and macro-scale reactions, and therefore would also be a potential candidate for diesel engine applications where ignition temperatures are similar.

\section{DESIGN AND FABRICATION OF SiCN MICRO GLOW PLUG}

Figure 2 shows a schematic and a scanning electron micrograph of a micro glow plug (MGP). The device consists of a single U-shaped layer of SiCN of thickness 30-300 microns. The tip cross sectional area is designed to be 10 times smaller than that of the wider arms, thus the circular electrical contact pads remain relatively cool while the tip glows upon passing a current through the device. This eliminates one problem found in conventional glow plugs, which is the need to insulate the electrical contacts while operating temperatures are achieved. Furthermore, because of its small size the MGP's response is almost instantaneous, and the device consumes very little power. In addition, only one material is required versus the three material needed to make a conventional glow plug, and the manufacturing is through a photolithography-based batch process therefore the manufacturing cost is significantly lower than that for the conventional devices.

The fabrication of SiCN MEMS is detailed elsewhere $[3,4]$. Basically, the fabrication comprises two major processes - a polymer process whereby polymeric structures in the shape of 
MGPs are fabricated from a liquid precursor, and then a ceramic process that consists of heating the polymer in a furnace to the pyrolysis temperature, at which the polymer decomposes into the amorphous SiCN ceramic.

The polymer micromachining process may be accomplished by two separate routes [4] - casting in micromolds fabricated from SU8 ${ }^{\mathrm{TM}}$ photoresist (from Micro Chem Corp), or by direct photopolymerization. The fabricated polymer structures are then removed from the substrate since they undergo $30 \%$ linear shrinkage during pyrolysis. This lack of substrate places a lower design limit on the size of the devices, since each component has to be assembled using manual pick and place. Thus, typical device dimensions range from tens of microns to hundreds of microns.

The polymeric components are then placed in a hot isostatic press (HIP, model AIP 6-30H from American Isostatic Presses) in a nitrogen atmosphere and pyrolyzed at $1000{ }^{\circ} \mathrm{C}$ for 4 hours. The polymer structure decomposes into a black-colored amorphous alloy of silicon, carbon and nitrogen. This ceramic is electrically insulating, hence the ceramic structures are then annealed at 1400 ${ }^{\circ} \mathrm{C}$ within the HIP to initiate nanocrystallization of electricallyconductive phases. X-ray diffraction strongly suggests that these nanophases are SiC. Room-temperature DC resistivity of 2-5 $\mathrm{Ohm}-\mathrm{cm}$ has been measured for material samples processed through this micromachining route [4].

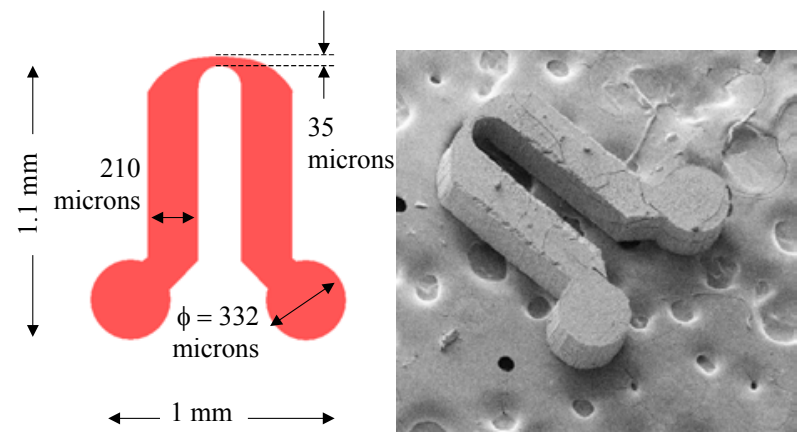

Figure 2. Schematic and scanning electron micrograph of the SiCN Micro Glow Plug (MGP).

Once the polymer MGP structures have been micromachined, they are packaged for testing. For probe-station testing, the devices were simply mounted on alumina substrates with epoxy. For ignition testing, the MGPs were packaged by attachment to photolithographically-patterned alumina substrates using silver paste, and then wirebonded to a commercial 14-pin ceramic dualin-line package (from Spectrum Semiconductor). Wires were then soldered to the pins on the package.

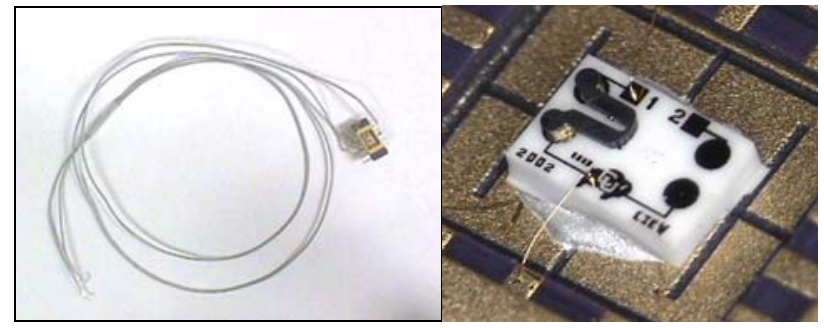

Figure 3. Left: MGP packaged for ignition testing. Right: close-up photograph of the package, showing a MGP mounted on an alumina substrate.

\section{DEVICE TESTING}

\section{Electrical Testing}

The MGPs were mounted individually on alumina plates using non-conductive epoxy so that the glow tip was suspended over the edge of the substrate for thermal isolation. The alumina substrates were then placed under a probe station and electrical probes were placed on the MGP's circular bond pads. The resistance throughout the MGPs ranged from 200-800 Ohms unactuated, depending on the device thickness.

The majority of devices tested in this work exhibited resistance of around $500 \mathrm{Ohms}$ when unactatued. A constant DC current was then applied to the MGPs until the tips were glowing brightly. The first signs of glowing was observed at $20 \mathrm{~mA}$, with white glow being achieved at 30-35 mA. Upon application of DC current, the response time to achieve white glow is less than 1 second from a "cold" start. Since in most ignition applications the devices would be operated in DC mode, and this response time is significantly faster than conventional glow plugs, more accurate measurements of response time were not done at this stage of the work. Furthermore, the power consumption (typically 2-5 Watts) is significantly lower than that of conventional glow plugs due to the small size. Figure 4 shows photographs of a MGP in the offand on state.

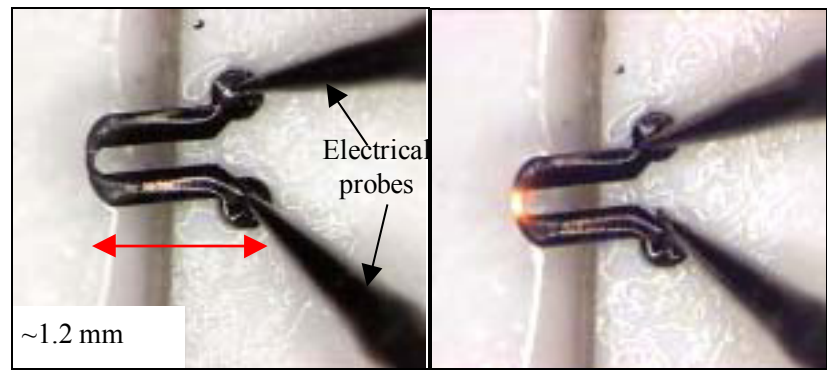

Figure 4. Micro Glow Plug in the "off" state (left) and the "on" state (right), upon application of $30 \mathrm{~mA}$ of DC current.

As the glow tip remains heated continuously, various microstructural changes occur within the material over time which cause the resistance to increase until the device fails, i.e. ceases to conduct current. The dominant failure mechanism is believed to be oxidation of the $\mathrm{SiCN}$ from the extremely high temperatures (modeled at above $1500{ }^{\circ} \mathrm{C}$ ) generated from the continuous induced heating, or from crack propagation.

The time to failure for several MGPs was measured for varying levels of applied DC current, the results being shown in Figure 5. Close-up SEMs of the glow tip following failure are shown in Figure 6, showing both an oxidation layer as well as cracks. Given the size of the cracks and the fact that the oxidation forms a layer rather than the core of the material, cracking was probably the cause of failure in this particular device. What temperature does the glow tip achieve during operation? Due to the small dimensions and high temperature of the glow tip, direct temperature measurements using pyrometers or thermocouples is technically difficult. While more sophisticated measurement techniques could be developed, the approach sought here was to indirectly measure the temperature by using the device to ignite or melt various materials whose melting or ignition temperatures are well documented. This would give a lower limit on the device temperature achieved during operation. This is described in the next section. 


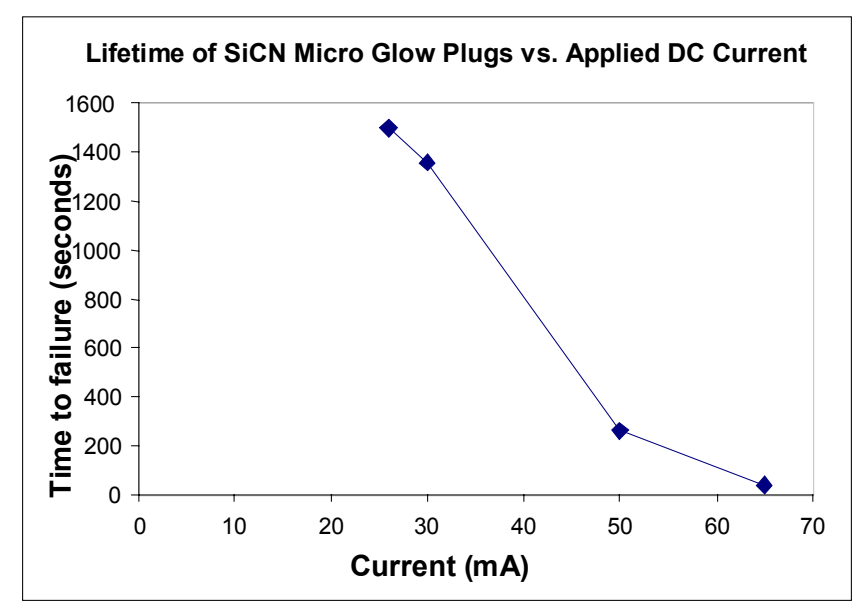

Figure 5. Micro Glow Plug lifetime as a function of applied DC current. The lines connecting the data points are to enhance clarity and do not represent intermediate data values.

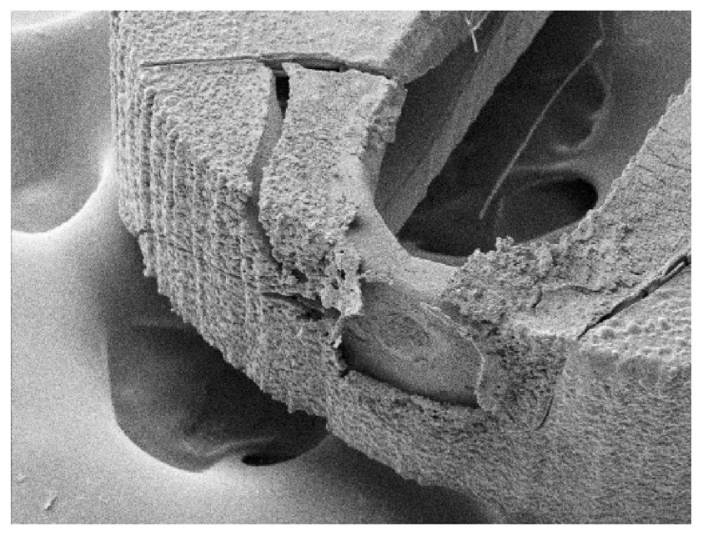

Figure 6. Scanning electron micrograph of a MGP tip following failure after. The thickness of this device is about about 200 microns.

\section{Ignition Testing}

In addition to the operational testing described in the previous section, the MGPs were also used to melt or ignite various materials. The purpose of these tests was twofold: to indirectly measure the temperature of the glow tip given the difficulties in direct measurement of such a small high-temperature region, and to demonstrate the functionality of the MGPs as high-temperature ignition devices.

The MGPs were used to ignite thermite [5]. Thermite is a solidstate explosive that has an ignition temperature of about $1200{ }^{\circ} \mathrm{C}$. Due to this high ignition temperature, thermite is commonly ignited with a strip of burning magnesium ribbon or other vigorous reactions. The thermite reaction itself is highly exothermic, producing temperatures above $2000{ }^{\circ} \mathrm{C}$. Uses of thermite include welding (known as the Goldschmidt process) and in military incendiary weapons.

In this experiment, thermite was made by mixing $\mathrm{Fe}_{2} \mathrm{O}_{3}$ with $\mathrm{Al}$ powder in a 3:1 ratio. When the temperature of the mixture is raised to above $1200{ }^{\circ} \mathrm{C}$ (the ignition temperature), an oxidationreduction reaction occurs resulting in molten iron:

$$
2 \mathrm{Al}(\mathrm{s})+\mathrm{Fe}_{2} \mathrm{O}_{3} \rightarrow \mathrm{Al}_{2} \mathrm{O}_{3}(\mathrm{l})+2 \mathrm{Fe}(\mathrm{l})
$$

Two variations of the thermite ignition experiments were done: a chip-level reaction and a larger scale reaction utilizing a greater mass of thermite. Both types of reactions were carried out using one MGP at a time.

In the chip-level ignition experiment, 5 milligrams of thermite was placed on the substrate within the package cavity so that the entire MGP and substrate were covered with thermite. The purpose was to demonstrate a chip-scale thermite reaction that would otherwise be inaccessible by conventional ignition means) due to the small size scale of MEMS. Potential applications of such chipscale thermite-type reactions could be as very powerful micro thrusters or micro power generators, given the violent nature of the thermite reaction. Figure 7 shows photographs of the reaction as captured on a digital video camera at 30 frames per second. Not shown are two intermediate frames of the reaction in which the extreme intensity of the light from the reaction saturated the camera, thereby producing no image. Figure 8 shows photographs of the MGP before and after the chip-scale reaction. After the reaction, all the gold on the alumina substrate, the surrounding area of the package cavity, and the wirebonds had melted and most of the package cavity was filled with the reaction byproducts solidified iron and gold, and aluminum oxide. Shock waves generated from the reaction scattered some of the powder on the periphery of the chip, thus the package cavity also contained some unreacted thermite. Due to the small amount of thermite used comparable to the weight of the MGP itself (which is $\sim 0.2$ milligrams) - the MGP remained intact and operational following the reaction. Therefore, for chip-scale reactions the thermal shock resistance and high-temperature stability of the MGP have been proven in operation, and the possibility of harnessing thermite reactions for MEMS-scale applications has been demonstrated.

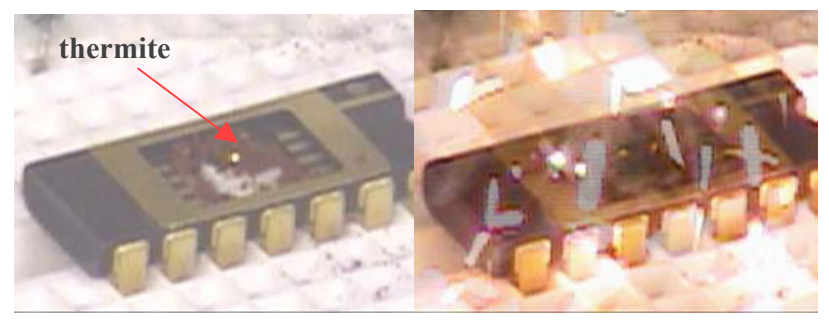

Figure 7. Chip-scale thermite reaction initiated by Micro Glow Plug. (a) MGP starting to glow, (b) ignition! The sequence took about 200 msec.

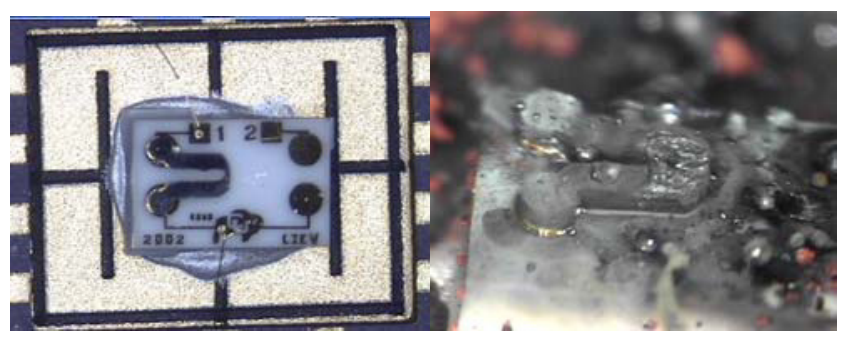

Figure 8. Micro Glow Plug before and after chip-scale reaction.

The MGP was then used to ignite 5 grams of thermite. This is 1000 times as much thermite as was used in the chip-scale reaction, and 25,000 times the mass of the MGP itself. Wires were soldered to the pins on the ceramic package, and the package was placed within a beaker (both glass and plastic beakers were used) and buried in the thermite. Due to the self-propagating nature of 
the thermite reaction, a single MGP operating at $25 \mathrm{~mA}$ was able to fully ignite all of the thermite, completely engulfing the ceramic package in molten iron. Figure 9 shows video stills of the reaction in the plastic beaker. There was no trace of the MGP or the ceramic package following this reaction. The MGP could have decomposed, been obscured by the molten slag, or been flung some distance from the reaction site by the pressure generated by the reaction (see Figure 10). Figure 10 is a video still showing the extent of the reaction within a $30-\mathrm{mL}$ glass beaker initiated by a single MGP. (Not shown are subsequent video stills in which the glass beaker and then the aluminum plate on which it was placed shattered from the extreme thermal shock.)

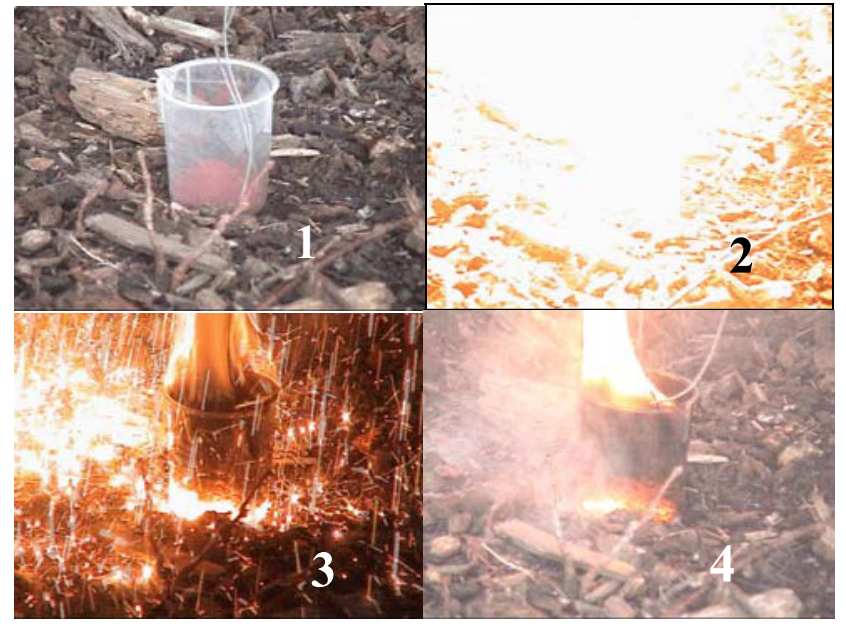

Figure 9. Micro Glow Plug igniting 5 grams of thermite in a plastic beaker.

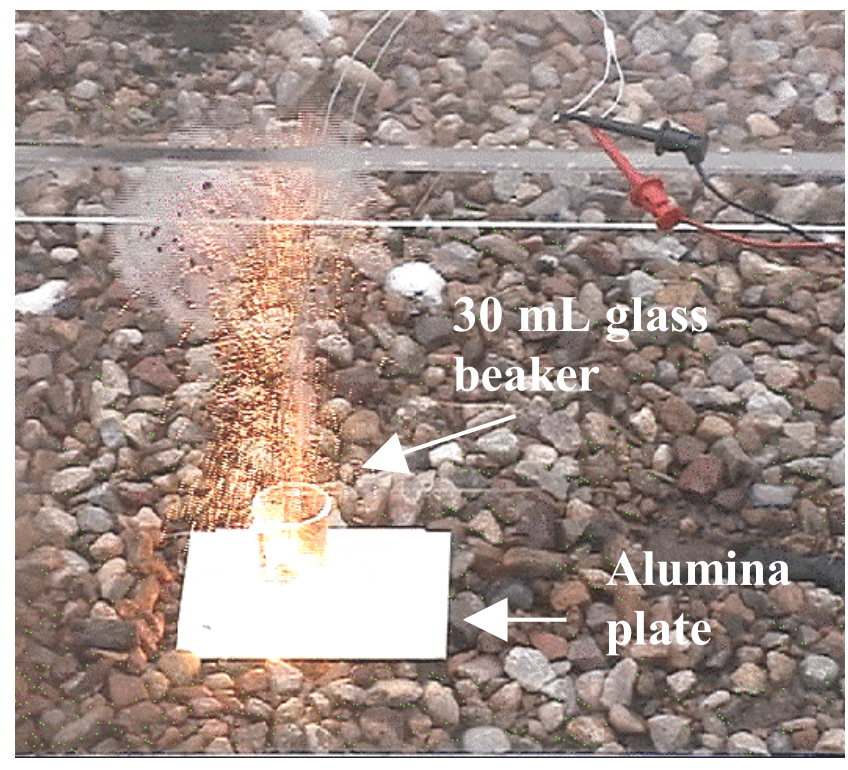

Figure 10. Larger view of thermite reaction within a glass beaker.

Therefore, the thermite experiments demonstrate the successful use of the MGP as a high-temperature igniter, at both the chipscale and at the macro-scale. In the macro-scale experiments the MGP successfully ignited thermite 25,000 times its own mass indicating its applicability to conventional diesel engine applications - but was then destroyed/engulfed by the reaction it initiated; however, in the chip-scale reaction where the amount of thermite used was only ten times the mass of the device itself, the MGP remained intact and functional following the reaction, suggesting the potential of harnessing the power of thermite-type reactions for micro-scale applications such as in micro thrusters.

This device therefore offers benefits to an application outside of the current MEMS industry (ignition in diesel engines), as well as enabling the integration of high-ignition temperature explosives into new MEMS-scale applications.

\section{SUMMARY AND CONCLUSIONS}

A Micro Glow Plug was designed and fabricated from polymer-derived SiCN ceramic. As summarized in Table 1, the MGP exhibits lower power consumption, faster response and less manufacturing complexity compared to conventional glow plugs while achieving the same operating temperature. The MGP was successfully used to ignite thermite (ignition temperature $1200{ }^{\circ} \mathrm{C}$ ) in chip-scale and macro-scale reactions. This device therefore represents a new class of harsh environment micro devices that have the potential to penetrate markets previously untouched by MEMS.

\begin{tabular}{|c|c|c|}
\hline & $\begin{array}{c}\text { Conventional } \\
\text { Glow Plugs }\end{array}$ & $\begin{array}{c}\text { SiCN } \\
\text { Micro Glow Plug }\end{array}$ \\
\hline Size & Length $30-50 \mathrm{~mm}$ & Length $1.1 \mathrm{~mm}$ \\
\hline Temperature & $1200^{\circ} \mathrm{C}$ & $1200^{\circ} \mathrm{C}$ \\
\hline Power Consumption & $100 \mathrm{Watts}$ & $3 \mathrm{Watts}$ \\
\hline Response Time & $5-10$ seconds & $<1$ second \\
\hline Fabrication & 3 materials & 1 material \\
Complexity & 3 processes & 1 process \\
\hline
\end{tabular}

Table 1. Comparison between conventional glow plugs and SiCN Micro Glow Plug.

\section{ACKNOWLEDGEMENTS}

This work is sponsored by the Defense Advanced Research Projects Agency (DARPA) and U.S. Air Force under contract \#F30602-99-2-0543. The authors would also like to thank Dr. R.A. Saravanan, Mr. Chris Yakacki, Ms. Samantha Watson and Mr. Seth Frader-Thompson (University of Colorado, Dept. of Mechanical Engineering) for valuable assistance in various aspects of this work.

\section{REFERENCES}

[1] M.L. Willi, B.G. Richards, "Design and Development of a Direct Injected, Glow Plug Ignition-Assisted, Natural Gas Engine," Journal of Engineering For Gas Turbines and PowerTransactions of the ASME 117 Vol. 4, pp. 799-803, 1995.

[2] L. An, R. Riedel, C. Konetschny, H.-J. Kleebe, R. Raj, , "Newtonian Viscosity of Amorphous Silicon Carbonitride at High Temperature, " Journal of the American Ceramic Society, Vol. 81, pp. $1349-52,1998$

[3] L.A. Liew, Y. Liu, R. Luo, T. Cross, L. An, V. M. Bright, M. L. Dunn, J. W. Daily and R. Raj, "Fabrication of SiCN MEMS By Photopolymerization of Pre-Ceramic Polymer," Sensors and Actuators, vol. A-95, no. 2-3, pp. 120-134, 2002.

[4] L.A. Liew, V.M. Bright, M.L. Dunn, J.W. Daily and R. Raj, "Development of SiCN Ceramic Thermal Actuators," Proceedings of the 15th Annual International Conference on Micro

Electromechanical Systems (MEMS2002), pp. 590-593, Las Vegas, Nevada, Jan 20-24, 2002.

[5] A. C. Davies, The Science and Practice of Welding, 8th ed. Cambridge University Press, New York, 1984. 